\title{
Administración Única y Pacto Local ${ }^{*}$
}

\author{
Jaime Rodríguez-Arana Muñoz \\ Catedrático de Derecho Administrativo \\ Subsecretario de Administraciones Públicas
}

Sumario: I. INTRODUCCIÓN. II. SOBRE LA SUBSIDIARIEDAD: a) Sobre el principio de subsidariedad, b) La Carta Europea de la Autonomia Local. III. ADMINISTRACIÓN ÚNICA Y ENTES LOC.ALES. IV. CUESTIONES COMPETENCIALES: a) Materias susceptibles de asignación a las Corporaciones Locales, b) Aspectos financieros. V. CONCLUSIONES.

\section{INTRODUCCIÓN}

El modelo de Administración que recoge la Constitución española de 1978 parte de la consideración de las Administraciones Públicas como organizaciones al servicio de los intereses generales, que actúan de acuerdo con los principios - para lo que ahora interesa- de descentralización y eficacia. En este sentido, no debe olvidarse que la actuación administrativa está presidida, en un Estado Social y Democrático de Derecho, por exigencias de calidad.

En realidad, el modelo de Administración tiene como punto de partida la constatación de que las Administraciones Públicas sean la parte más próxima y visible al ciudadano de todo el aparato público. Por eso, es necesario buscar, por supuesto en el marco constitucional, fómulas organizativas que hagan realidad los objetivos constitucionales referidos a todo el quehacer de nuestras Administraciones Públicas.

La Constitución de 1978 en su artículo 137 reconoce, como es sabido, la autonomía de las Corporaciones Locales para la gestión de sus intereses y es evidente que de este principio han de derivarse importantes consecuencias para la articulación del sistema de competencias locales.

Sin embargo, respecto a las Entidades Locales, la Constitución garantiza la autonomía local pero no señala un listado concreto de materias sobre las que pueda ejercerse dicha autonomía.

El autor agradece a Pedro Ibánez Buil, Funcionario del Cuerpo Superior de Administradores Civiles del Estado, su valiosa colaboración para la realización de este estudio. 
En el mismo sentido se expresa la Sentencia 27/1987 del Tribunal Constitucional cuando dice:

«Como este Tribunal ha precisado en varias ocasiones (STC 4/81), dicha autonomía hace referencia a la distribución territorial del poder del Estado en el sentido amplio del término, y debe de ser entendido como un derecho de la comunidad local a participar a través de sus órganos propios en el gobierno y administración de cuantos asuntos le atañen constituyendo en todo caso un poder limitado que no puede oponerse al principio de unidad estatal.»

Como señala SÁNCHEZMORÓN la Constitución no identifica la autonomía local con la separación de una esfera de actuación reservada por entero a las administraciones locales con exclusión de toda incidencia de otros niveles de gobierno y de gestión de los intereses públicos. No impone una concepción de la autonomía como absoluta libertad de decisión, según esquemas dificilmente operantes en el Estado Social y Democrático de Derecho. La Constitución legitima, en cambio, cuando no impulsa, una concepción articulada de la autonomía como participación de diversas instancias territoriales de gobierno en la ordenación y prestación de los servicios públicos ${ }^{1}$.

La Ley de Bases del Régimen Local de 1985, valga la redundancia, se presenta como la norma encargada de concretar las bases del régimen jurídico de la Administración Local, con el objetivo prioritario de dar efectividad a la garantía institucional de la autonomía local.

Pues bien, la autonomía local, desde esta aproximación, pretendía garantizarse por un lado fijando unas mínimas competencias y, por otro, estableciendo el derecho a participar en la gestión de los asuntos públicos que sean de interés de las respectivas entidades; es decir, se trataba, en definitiva, de fijar criterios a la legislación sectorial estatal y autonómica para que ésta, a su vez, concretase las competencias con que las Corporaciones Locales debian contar para dicha gestión.

Es la denominada garantía institucional de la autonomía local. En palabras de SOSA WAGNER ${ }^{2}$ la garantía institucional es una técnica que permite proteger a ciertas instituciones a las que se considera como componentes esenciales de la organización jurídico-política y cuya preservación se juzga indispensable para asegurar los preceptos constitucionales. Se otorga un am-

' M. SÁnchez Morón, La Autonomia Local, Civitas, 1989, pág. 200.

2 F. SOSA WAGNER, «La Autonomía Local», en Estudios sobre la Constitución Española. Homenaje al Profesor García de Enterría, Civitas, 1991, pág. 3.213. 
plio margen de conformación al legislador que utilizará correctamente, es decir, sin violentar el texto constitucional, siempre que preserve el núcleo esencial que la Constitución garantiza.

No obstante, esta teoría de la garantía institucional se ha revelado insuficiente desde una óptica constructiva o positiva - la figura sólo establece límites pero no permite atribuir contenidos-, ya que parece inadecuada cuando se pretende avanzar en la resolución de todos los aspectos que hacen que la inserción de la Administración Local en el Estado Autonómico sea aún una cuestión relativamente abierta.

Así pues, parece evidente la incapacidad de los mecanismos arbitrados por la Ley de Bases para hacer frente a las cada vez mayores demandas de los ciudadanos; limitaciones que se refieren tanto al nivel de atribución competencial como a la capacidad financiera de las Corporaciones Locales.

Ante esta situación se ha ido desarrollando en los últimos tiempos una pluralidad de iniciativas, aproximaciones, reflexiones y propuestas encaminadas todas ellas, en su conjunto, a replantear las relaciones que deben regir la posición respectiva de las Comunidades Autónomas y de las Entidades Locales y aun quizás a replantear la posición del sistema local en el conjunto del ordenamiento autonómico del Estado ${ }^{3}$.

El punto común consiste en destacar la necesidad de impulsar un proceso de signo descentralizador hacia las Entidades Locales, una vez comprobado que la consolidación de las Comunidades Autónomas les ha permitido alcanzar una situación en la que gestionan o van a gestionar un elevado volumen de gasto público, en cualquier caso muy superior al que gestionan las Entidades Locales.

Se trataría, en definitiva, de hacer operativa la autonomía local a través de los principios constitucionales de pluralismo político, de estructura democrática de la Administración municipal, de eficacia en el servicio objetivo de los intereses generales y de descentralización.

Después de la importante descentralización operada por el Estado a las Comunidades Autónomas podemos considerar que va llegando el momento de la Administración local, ya que el proceso de descentralización que trae consigo la puesta en marcha de la llamada Administración Única no debe detenerse en el escalón autonómico, sino que debería plasmarse en el ámbito local.

3 Véase. por ejemplo, el documento Bases para el Pacto Local, aprobado por la Comisión Ejecutiva de la FEMP en su reunión del dia 24 de septiembre de1996. 
Consecuentemente, esta visión tiene su expresión en el artículo 30 de la recientemente aprobada Ley de Organización y Funcionamiento de la Administración General del Estado (LOFAGE) que prevé la reestructuración y simplificación de los servicios periféricos cuya subsistencia resulte innecesaria a la vista de las competencias transferidas o delegadas a las Comunidades Autónomas y a las Entidades Locales.

Es de destacar en el precepto que se plasma la visión del Gobierno entendiendo la Administración Única como un proceso en varias direcciones, de manera que la descentralización en el escalón local, quizá la más importante, también se contemple como elemento medular de la Administración Única.

\section{SOBRE LA SUBSIDIARIEDAD}

\section{a) Sobre el principio de subsidiariedad}

La Administración Única implica, es claro, una aplicación del principio de subsidiariedad, principio del que se ha dicho que no es más que una palabra larga para resumir dos ideas simples: que la autoridad debe ejercerse en el nivel más adecuado para la más eficiente aplicación de las medidas de que se trate; y que el Gobierno, de cualquier clase, debe completar, no sustituir, la acción de los individuos y de los cuerpos intermedios.

El principio de subsidiariedad, pues, está en la entraña del Estado Social y Democrático de Derecho y confirma la idea de que el Estado, los Poderes Públicos, existen para servir al ciudadano y no el ciudadano para el Estado. Además y ello es importante, ese servicio debe prestarse de la forma más eficaz y por quien sea más eficaz, precisamente para conseguir calidad en el servicio a los ciudadanos.

La subsidiariedad postula que, en principio, la ordenación política administrativa y los correspondientes ordenamientos jurídicos se construyan de abajo arriba, resolviendo en cada nivel cuanto sea posible, lo más cerca de la base y de los legítimos intereses correspondientes.

Ahora bien, que se postule la resolución de los problemas colectivos en el nivel político-organizativo más próximo a los ciudadanos, no es sino trasunto, lógico, de la importancia del ciudadano, del hombre, en todo el sistema político administrativo. En este sentido, no conviene olvidar que el principio de subsidiariedad señala que la responsabilidad individual precede a la responsabilidad global, de forma que cuanto más próximo sea el nivel de la resolución de los 
ADMINISTRACIÓN ÚNICA Y PACTO LOCAL

asuntos públicos parece evidente que puede acrecentarse esa responsabilidad individual.

El principio de subsidiariedad, lógicamente, limita considerablemente la operatividad del poder público y tiene tres importantes corolarios; primero: un sistema social es tanto más perfecto cuanto menos impida a los individuos la consecución de sus propios intereses. Segundo: un sistema social será más eficaz cuanto menos acuda a las leyes y más a la acción de fomento y a los estímulos para alcanzar el bien común. Tercero y muy importante: un sistema social es tanto más valioso cuanto más se utilice la técnica de la descentralización del poder y se dote de mayor autonomía a las Comunidades Menores.

En el fondo, como es sabido, el fundamento del principio de subsidiariedad es la satisfacción del bien común, la consecución de las necesidades colectivas, lo que justifica que su tutela, gestión y promoción se encuentre en las instancias más próximas a los ciudadanos.

En especial, vamos a centrar nuestra atención en esa segunda dimensión de la subsidiariedad que se refiere a que la autoridad debe ejercerse en el nivel más adecuado para la más eficiente aplicación de las medidas de que se trate.

\section{b) La Carta Europea de la Autonomía Local}

Es de gran interés, al tratar del principio de subsidiariedad y su relación con las Entidades Locales, hacer referencia a la Carta Europea de la Autonomía Local.

Elaborada en el marco del Consejo de Europa, su trascendencia es innegable, puesto que se trata de un texto normativo incorporado a nuestro Derecho interno y por tanto plenamente invocable ante los Tribunales de Justicia espanoles. Esta invocabilidad es, precisamente, una de las características que le otorga mayor actualidad y justifica que le dediquemos nuestra atención.

Entre los principios que la Carta Europea de la Autonomía Local consagra, destacan la suficiencia de recursos, la autonomía para el gasto y el ingreso, el derecho a ser oído cuando se dicten medidas y criterios de redistribución de los recursos, la preferencia de subvenciones y el libre acceso al mercado para concretar operaciones de crédito destinadas a gastos de inversión.

Pero, en definitiva, lo que la Carta nos viene a decir es que las Entidades Locales ordenan y gestionan los asuntos públicos en beneficio de sus habitantes y que sus órganos de gobierno son directamente representativos de dichos 
ciudadanos. Ello viene a suponer, en definitiva, la asunción de competencias propias sobre la parte importante de los asuntos públicos y la financiación suficiente para ejercitarlos.

Una de las proyecciones más significativas de la Carta es la mayor efectividad que la misma puede dar al artículo 2.1 de la Ley de Bases. Es indudable que este artículo se encuadra dentro de los principios de descentralización y de máxima proximidad de la gestión administrativa a los ciudadanos, constituyendo, sin duda, la formulación interna del principio de subsidiariedad en su aplicación sobre el legislador estatal y autonómico respecto de los Entes Locales: con ello se erige en parámetro de interpretación y aplicación que ha de quedar reforzado con el impulso europeo que deriva de la Carta Europea de Autonomía Local ${ }^{4}$.

En la Carta se parte directamente de dos principios: uno, que ya ha sido mencionado anteriormente, el de subsidiariedad y otro, el de proximidad, la cercanía a los ciudadanos como criterio de atribución competencial. Así se expresa en el punto primero del apartado tercero del artículo cuarto de la Carta, al establecer que:

«El ejercicio de las responsabilidades públicas debe, de modo general, incumbir preferentemente a las autoridades más cercanas a los ciudadanos.»

Al mismo tiempo, el mismo apartado tercero en su punto segundo exige que:

«La atribución de una responsabilidad a otra autoridad debe tener en cuenta la amplitud o la naturaleza de la tarea o las necesidades de eficacia o economía.»

A lo anterior se añaden otros tres elementos normativos. De una parte, la potestad reglamentaria se realiza según el artículo 3 de la Carta «en el marco de la Ley». De otra, la libertad de los Entes Locales para ejercer su iniciativa en toda materia que no esté excluida de su competencia o atribuida a otra autoridad. Finalmente, se establece una reserva reglamentaria en materia de organización local.

La Carta afirma el principio de autogobierno, al establecer el ya citado artículo 3 que la gestión de los asuntos públicos la realizará el ente local bajo su propia responsabilidad. Este principio de autogobierno es, sin duda, un instru-

4 T. Font y Llovet, «El Gobiemo Local: entre el Estado autonómico y la Unión Europea. Hacia el Pacto Local», Autonomies, n. ${ }^{\circ} 20$, pág. 114. 
mento interpretativo fundamental con relación al régimen de las competencias de los entes locales.

Asimismo, la propia Carta recoge, como no podía ser de otra forma, el principio de subsidiariedad al contemplar la proximidad a los ciudadanos como criterio de atribución competencial, estableciendo que el ejercicio de las competencias públicas debe de modo general incumbir preferentemente a las autoridades más cercanas a los ciudadanos. Se trata, así, de acercar la Administración al ciudadano. Algo que aquí, en España, se ha dado en llamar la Administración Única.

\section{ADMINISTRACIÓN ÚNICA Y ENTES LOCALES}

En el fondo, la Administración Única, que es una reflexión general sobre el funcionamiento del aparato público, intenta clarificar el margen de actividad de los poderes públicos para que, de acuerdo con el momento de evolución de nuestro sistema, Estado, Comunidades Autónomas y Entes Locales, puedan desarrollar mejor su función constitucional. Quiero volver a recordar en este punto que la Administración Única es favorable al reforzamiento de los Entes Locales.

Y lo es porque la Administración Única exige necesariamente que sean los Entes Locales los que presten un mayor número de servicios y operen una elevada carga administrativa. La doctrina de la Administración Única supone, pues, un claro reforzamiento del ente titular de competencias en su propia demarcación territorial, lo cual debe propiciar un mayor protagonismo de Ayuntamientos y Diputaciones en el ejercicio de las competencias sobre su propio territorio.

De lo anterior se sigue que la Administración Única no es incompatible con la función que la Constitución asigna a las Corporaciones Locales y singularmente a los Ayuntamientos y Diputaciones. Muy al contrario, ya que el proceso de redistribución de competencias no se completaría si no se produjese un proceso paralelo de desconcentración de competencias de la Administración Autonómica hacia las Administraciones Locales, en todos aquellos servicios en que su prestación por estos entes redundara en un mejor servicio al ciudadano, que es en definitiva la pieza clave del sistema en función del cual debe reorientarse todo el aparato administrativo.

Es importante señalar, en este punto de la exposición, que la doctrina de la Administración Única parte de un dato capital: el mejor servicio al ciudadano. Es una propuesta que permite pensar en una nueva manera de administrar, más pen- 
diente de la persona y de sus derechos fundamentales que de la propia problemática organizativa. Se trata, en definitiva, de dar un paso más en esa eterna lucha por hacer una Administración Pública más humana, más pendiente del hombre concreto; siempre teniendo presente que un sistema social es tanto más valioso cuanto más se valgan las autoridades centrales y regionales de las locales 5 .

Siendo ello así, al haberse producido en España un proceso de distribución territorial del poder con el desarrollo del fenómeno autonómico, resulta necesario que se reconozca, en esta estructuración del reparto del poder político establecido por la Constitución, un lógico protagonismo de las Entidades Locales.

Sin embargo, durante mucho tiempo se ha prestado una atención más que prioritaria a la descentralización de competencias del Estado hacia las Comunidades Autónomas, con un cierto olvido de las Entidades Locales.

Es cierto, como es bien sabido, que la Constitución no ha establecido un listado de materias sobre las que los Entes Locales ejerzan sus competencias; pero también es posible - y deseable - que se ponga en marcha, una vez que el contenido propio de las autonomías esté bien definido, una auténtica descentralización hacia los Entes Locales, habida cuenta que es habitualmente el legislador sectorial autonómico quien tiene la última palabra sobre la funcionalidad competencial de los Entes Locales.

Además de la Constitución, las propias Comunidades Autónomas contemplan en sus Estatutos una descentralización de funciones hacia los Entes Locales. De lo que se trata, en definitiva, es de aceptar que la Administración Local es, en aplicación del principio de subsidiariedad, la Administración ordinaria o común en el Estado de las Autonomías.

Especial relevancia adquiere en este aspecto el papel del segundo escalón de la Administración Local, es decir, la provincia, para la plena realización de la autonomía local. La Administración Única, no lo olvidemos, no se agota en el escalón autonómico, sino que debe continuar en el ámbito local. Por eso la puesta en marcha de esta propuesta pone de actualidad una de las grandes directrices de reforma que se propuso en el informe elaborado en 1981 por la denominada Comisión de expertos sobre Autonomías, presidida por el profesor GARCIA DE ENTERRIA al sugerir la conversión de las Diputaciones Provinciales en gestores ordinarios de las competencias autonómicas tanto estatutarias como delegadas.

5 J. MESSNER, Ética juridica, Madrid, 1969, pág. 126. 
Dicha instancia supramunicipal podría ser utilizada por las Comunidades Autónomas para la ejecución y prestación en el ámbito territorial de aquellas de las competencias y servicios propios de dichas Comunidades, evitando así la superposición innecesaria de Administraciones Territoriales, incrementando la eficiencia de las Administraciones Públicas y acercando al máximo la Administración al ciudadano.

En otras palabras, en realidad se trata, fundamentalmente, de pensar en la posibilidad de que las Comunidades Autónomas desconcentrasen su administración periférica en las Diputaciones, para lo cual podria ser de interés que se pusieran en marcha leyes autonómicas que operen una auténtica descentralización hacia los Entes Locales. Además, no debe olvidarse que el artículo 8 de la Ley del Proceso Autonómico permite que las Comunidades Autónomas deleguen en las Diputaciones Provinciales, según la naturaleza de la materia, el ejercicio de competencias transferidas o delegadas por el Estado a aquéllas salvo que la Ley a que se refiere el artículo 150.2 de la Constitución Española disponga otra cosa ${ }^{6}$.

Este proceso debería realizarse evitando duplicidades, $\mathrm{y}-$ como necesario corolario - acompañado de la descentralización del gasto, posibilitando así que las Entidades Locales puedan efectivamente cumplir sus fines y ejercer sus competencias de conformidad con lo previsto en la Ley 7/1985.

\section{CUESTIONES COMPETENCIALES}

\section{a) Materias susceptibles de asignación a los Entes Locales}

En lo referente a cuestiones competenciales, desde el propio Parlamento se ha instado a la redefinición del marco competencial en base al principio de subsidiariedad; en este sentido, el significado del pacto local es, pues, dar respuesta a la insuficiencia de los instrumentos jurídicos para definir positivamente y hacer eficaz el contenido competencial concreto que la autonomía local reclama para la gestión de los intereses propios.

Como nos encontramos, al tratar de la Administración Única, en un contexto administrativo nos interesa ahora tratar el tema de las funciones administrativas que puedan ser delegadas o transferidas correspondientes a materias de titularidad estatal y autonómica.

6 M. Fraga, «Administración Única: una propuesta de racionalización del Estado de las Autonomias»). Debate sobre la situación del Estado de las Autonomías. Comisión General de las Comunidades Autónomas del Senado, 26 de septiembre de 1994. 
El objetivo primero ha de consistir en delimitar aquellas materias y funciones en relación con las cuales cabe prever una asignación a los entes locales. En este sentido, las competencias deben estar referidas a lo que es la prestación del servicio, sin perjuicio de que las competencias de ordenación general puedan seguir siendo ejercidas por la Administración estatal o autonómica titular de la competencia y de que la atribución de la correspondiente potestad planificadora dentro de su ámbito territorial se desarrolle en el marco de la planificación general del titular de la competencia.

Otra cuestión es determinar cuál es el método más idóneo para proceder a dicha atribución competencial. A este respecto caben varias posibilidades con la utilización de figuras como la transferencia de competencias, la delegación, la encomienda de gestión o los convenios y conciertos como mecanismos adecuados de cooperación, especialmente cuando se trate de la prestación de servicios compartidos o complementarios entre varias Administraciones.

¿Cuáles serían las materias que bien pueden gestionar los Entes Locales en virtud del elemento territorial y del interés propio? La Federación Española de Municipios y Provincias las divide en las siguientes áreas: deportes, educación, empleo, servicios sociales, juventud, mujer, señalando como especialmente prioritarias las relacionadas con aspectos urbanísticos, transporte y vialidad, seguridad ciudadana y turismo ${ }^{7}$. Como se puede comprobar, se trata de materias, muchas de ellas competencia de la Comunidad Autónoma o en algún caso del Estado o compartidas o concurrentes, por lo que la atribución lo será siempre sin perjuicio de la titularidad autonómica, con todo lo que eso supone.

La realidad municipal española exige, por otro lado, que la delimitación de funciones y materias trasladables al ámbito del Gobierno local se lleve a cabo teniendo en cuenta la efectiva capacidad de gestión, tomada como medida en las competencias que incorporan prestaciones de servicios, calibrada ya sea a través del número de habitantes, ya sea por el volumen, dentro del presupuesto anual, ya sea por la verificación de la efectiva implantación y dimensión de los servicios obligatorios; pero también ha de tenerse en cuenta la inserción de los Municipios en estructuras de segundo grado eficientes; esto es, huir de la consideración aislada del Municipio y reflexionar acerca del papel de las Mancomunidades de Municipios y sobre todo de las Diputaciones Provinciales, como entidades de apoyo a los Municipios para una correcta prestación de los servicios que éstos tengan encomendados.

7 Véase documento Bases para el Pacto Local, págs. 8 y ss. 
ADMINISTRACIÓN ÚNICA Y PACTO LOCAL

\section{b) Aspectos financieros}

En cuanto a la efectividad de las competencias o funciones reconocidas a los Municipios, no hay duda de que su transferencia o reconocimiento debería acompañarse del trasvase de los medios correspondientes, especialmente en materia financiera. Este es un punto extremadamente delicado y de cuya correcta resolución depende en buena medida el éxito del proceso descentralizador. A este respecto, hay que recordar que el artículo 142 de la Constitución dispone que las Haciendas Locales deberán disponer de medios suficientes para el desempeño de las funciones que la ley les atribuye y que las mismas se nutrirán fundamentalmente de tributos propios y de participación en los del Estado y de las Comunidades Autónomas.

Suficiencia financiera que se recoge tanto en la Ley 39/1988, reguladora de las Haciendas Locales, como en la propia Carta Europea de la Autonomía Local, en la que se establece que los recursos financieros de las Entidades Locales deben ser proporcionales a las competencias previstas por la Constitución o por la Ley.

Este principio de suficiencia financiera determina que las Entidades Locales deben tener garantizados constitucionalmente recursos suficientes en relación con sus funciones, por lo que una definición del nuevo mapa competencial de las Entidades Locales ha de tener en cuenta la asignación de los recursos financieros suficientes para dar cumplimiento a los principios de autonomía y subsidiariedad en el ámbito de las Entidades Locales.

En España, los recursos propios de los Municipios constituyen algo menos de la mitad de sus ingresos, mientras que la media de los países occidentales asciende a más del $70 \%$. La actual participación en los ingresos del Estado debería irse trasladando hacia las Comunidades Autónomas, las cuales ya han comenzado a constituir fondos autonómicos de cooperación local. Al mismo tiempo, el Estado ha realizado últimamente un esfuerzo para incrementar la participación en la financiación local, incluso con la aportación de fondos europeos, lo que coincide en el tiempo con la coordinación del acceso de los Entes Locales a dichos fondos.

\section{CONCLUSIONES}

La mayor proximidad de los Municipios a los intereses ciudadanos tendría que proyectarse en una descentralización de funciones y competencias en favor de las Entidades Locales, extrayendo en su plenitud las posibilidades de delegación de competencias estatales o autonómicas en su favor y abordando, si ello fuera preci- 
so, las reformas legales necesarias para alcanzar ese objetivo. El objetivo general en este ámbito es, pues, el reforzamiento de los Entes Locales, de forma que puedan asumir el protagonismo que les corresponda en todas las materias susceptibles de gestión en el orden local. Ello plantea la necesidad de alcanzar un Pacto Local, de carácter político y territorial, que permita abordar de un modo lógico, claro y de forma conjunta el futuro, las competencias y la posición de las Entidades Locales y que ha de basarse en una serie de principios, entre los que pueden citarse: la autonomía en la gestión de los intereses propios, la subsidiariedad, la descentralización y el acercamiento de la gestión, la eficacia en el desempeño de la función, la eliminación de duplicidades y la cooperación y coordinación ejecutivas.

La potenciación de los Entes Locales va ligada al concepto de Administración Única y al denominado principio de subsidiariedad, de acuerdo con el cual la prestación de los servicios públicos debe llevarse a cabo por la Administración que se encuentre en mejores condiciones para ello y más próxima al ciudadano; el nivel administrativo superior actuará solo cuando la acción del inferior resulte insatisfactoria o ineficaz. Todo ello determina la necesidad de abordar de un modo global la redefinición del papel de las Entidades Locales en un Estado compuesto como es el nuestro, pues bueno es profundizar en el principio descentralizador hacia las Comunidades Autónomas, pero igualmente necesario parece el desarrollo de este principio respecto a las Entidades Locales pues la conciencia y lealtad al sistema supone su extensión hacia éstas.

Los artículos 25, 26 y 36 de la Ley de Bases de Régimen Local establecieron un mínimo competencial, remitiéndose al legislador sectorial competente - central o autonómico - para la determinación concreta de las competencias locales. En realidad, dada la escasa conexión de lo local con las materias exclusivas del Estado, y teniendo en cuenta que en los casos de competencias compartidas entre el Estado y las Comunidades Autónomas sólo puede el Estado atribuir competencias a los Entes Locales cuando sea necesario para garantizar la autonomía, resulta que es el legislador sectorial autonómico quien tiene la última palabra sobre la funcionalidad competencial de los Entes Locales.

La garantía institucional de la autonomía local reconocida en la Ley de Bases del Régimen Local puede servir como criterio de control a posteriori respecto de la legitimidad de las leyes que no reconozcan las competencias locales necesarias para la gestión de los asuntos locales. Pero a partir de ahí se hace necesario el recurso al más amplio acuerdo entre las fuerzas políticas, el Estado, las Comunidades Autónomas y las Entidades Locales con la finalidad de asumir el compromiso de profundizar la descentralización hacia el sistema de gobierno local. 
No estará nunca completa la reforma del Estado si ésta se limitase a abordar los aspectos relativos a las Comunidades Autónomas y sus relaciones con la Administración Central, sino que es necesario contemplar también y simultáneamente la posición y la articulación de los Entes Locales con las demás Entidades Territoriales. El reparto competencial existente entre el Estado y las Comunidades Autónomas determina que sean éstas las titulares de la mayor parte de las competencias susceptibles de atribución a los Entes Locales, por lo que resulta imprescindible, no sólo la participación de las Comunidades Autónomas, sino el acuerdo entre todas ellas, para que este proceso descentralizador opere uniformemente en todo el territorio.

El significado del Pacto Local es, pues, dar respuesta a la insuficiencia de instrumentos para definir positivamente y hacer eficaz el contenido competencial concreto que la autonomía local reclama para la gestión de los intereses propios ${ }^{8}$.

El Estado ha de participar activamente en este proceso como impulsor del mismo y mediante la aprobación de las normas relativas a aquellas materias cuya competencia le corresponde, pero no puede, unilateralmente, lograr la consecución del Pacto Local y del proceso global descentralizador que el mismo entraña sin la voluntad de colaboración de las Comunidades Autónomas.

Por tanto, parece ineludible y necesario intentar que se consiga un acuerdo entre las fuerzas políticas para que una serie de competencias que en este momento ejercen la propia Administración del Estado o las Comunidades Autónomas pasen a ser ejercidas por las Entidades Locales.

A este respecto, habrá que prestar atención a la labor de los distintos grupos de trabajo en los que deben participar Corporaciones Locales, Comunidades Autónomas y Administración del Estado al objeto de estudiar cuestiones tales como las materias y funciones que siendo competencia de la Administración General del Estado pueden delegarse a los Ayuntamientos, las normas del Estado que pueden afectar a las Corporaciones Locales y que afectan a elementos esenciales para el funcionamiento del sistema en su conjunto o los criterios de las Comunidades Autónomas para estudiar lo que la legislación autonómica puede hacer a los efectos de abordar la problemática municipal.

Lo cierto es que parece haber llegado ya el momento de proceder a un amplio acuerdo político y territorial que posibilite que los Entes Locales ocupen un lugar en el contexto organizativo, institucional y competencial acorde con sus capacidades y en función de esa cercanía al ciudadano, origen y destino de

8 T. Font Llovet, op cit., pág. 115. 
toda mejora territorial. Un pacto que beneficiará al conjunto del Estado, que contará con unas Entidades Locales ágiles y eficaces, incardinadas plenamente en el contexto estatal y de acuerdo con el principio de subsidiariedad.

En fin, el modelo de la Administración Única no se completaría si no se produjese un paralelo proceso de desconcentración de competencias de la Administración Autonómica hacia los Ayuntamientos y Diputaciones en todos aquellos servicios en que su prestación por estos entes redunde en un mejor servicio al ciudadano que es, en definitiva, la pieza clave del sistema y en función del cual debe reasentarse todo el aparato administrativo 9 .

La doctrina de la Administración Única parte, pues, de un dato capital: el mejor servicio al ciudadano, al hombre. Es una propuesta que permite pensar en una nueva manera de administrar, más pendiente de la persona y de sus derechos que de la propia problemática organizativa. Se trata, pues, de un paso más en esa eterna lucha por hacer una Administración Pública más humana, más pendiente del hombre concreto ${ }^{10}$.

9 F. Serna Gómez, Administración Única para Galicia: una propuesta abierta, EGAP 24 sept. 1992, pág. 3.

10 J. Rodriguez-Arana MuÑoz, La Administración Única en el Marco Constitucional, Santiago de Compostela 1993, pág. 156. 